\title{
A Comparison between Single Port and the Traditional Multiport Technique for Colon Resections
}

\author{
Idit Melnik MD ${ }^{1}$, Oleg Dukhno MD¹, Ornit Cohen M.MED Sc ${ }^{2}$, Dimitry Goldstein MD ${ }^{1}$ \\ Moris Batumsky ${ }^{1}$,Boris Yoffe MD FACS ${ }^{1}$ \\ ${ }^{1}$ Department of General and Vascular Surgery \\ ${ }^{2}$ Department of Clinical Research, Barzilai university Medical Center, Ashkelon, Israel. \\ melnik.idit@gmail.com
}

\section{Abstract:}

Purpose: single incision laparoscopic technique is an emerging modality. The purpose of our study was to compare the intraoperative and short-term postoperative outcomes of single incision laparoscopic colectomy (SILC) versus multi-incision laparoscopic colectomy (MILC) and to explore whether, for any of the different types of colectomies, SILC is the recommended approach.

Methods: We retrospectively reviewed the charts of all patients who underwent laparoscopic colectomies between October 2010 and December 2012. The cohort was divided into two groups, SILC and MILC, which were compared in terms of their intra-operative and early postoperative outcomes. Each group was then sub-divided according to the type of procedure, each of which was compared separately between SILC and MILC. The intra-operative parameters were total operative time, surgical margin involvement and the number of lymph nodes extracted. The postoperative parameters included length of hospital stay, 30-day readmission, maximum pain score, morbidity, and mortality.

Results: Seventy-five patients underwent laparoscopic colectomies (SILC-21/ MILC-54). Between the two groups, patient characteristics were not statistically different. A comparison of the groups' intraoperative and postoperative results showed no statistically significant differences. There were no deaths in either group. Analyses of each procedure separately showed that when performing RH there was a trend $(p=0.08)$ of better oncological results with a higher mean number of lymph nodes extracted ( $23.5 \pm 3.16 \mathrm{vs} .17 .19 \pm 6.93)$. In addition, LOS decreased ( $5.91 \pm 3.59$ vs. $6.48 \pm 1.76$, respectively), which was statistically significant ( $p=0.05)$.

Conclusions: Single incision approach for bowel resections is feasible and safe. Given our findings, we believe that SILC technique is an effective alternative to MILC when performing RH with the statistically significant benefits of lower LOS and better oncological results. However, the efficiency of the technique in LH or AR is still questionable and needs further evaluation.

Key words: single incision laparoscopic surgery; colorectal cancer; laparoscopic colectomy; righthemicolectomy; left hemicolectomy; minimally invasive surgery

In the past two decades, laparoscopic techniques have gained wide clinical acceptance in surgical practice. Compared to the traditional open approach, the laparoscopic approach in colorectal surgery has been shown to result in faster return of bowel function, shorter length of hospital stay (LOS), reduced postoperative pain, decreased wound complication, and better cosmetic results [1-5].

The first report of a single incision laparoscopic (SIL) surgery was in gynecology 20 years ago [6]. Seven years later, Bresadola et al. reported the successful use of SIL in a general surgical procedure for cholecystectomy 
[7]. Since then, SIL surgery has become an emerging modality that has gained widespread acceptance. SIL colectomy (SILC) has been described in case reports and case series [8-14]. These authors reported a trend of superiority of the SIL compared to the multi-port technique in reduced pain, better cosmetic results, and decreased LOS. However, other reports showed equivalent outcomes between the two techniques [15-16].

In light of contrasting data in literature, two questions arise. First, is SILC really superior and a bridge technique between conventional laparoscopic colectomy and natural orifice transluminal endoscopic surgery (NOTES), or is it merely a fashionable technique with no actual benefits? Second, among the different types of colectomies, is there a specific procedure in which the SILC is recommended?

The purpose of our study was to address this question by comparing the intraoperative and short-term postoperative outcomes of SILC compared to the multi-port technique.

\section{PATIENTS AND METHODS}

We retrospectively reviewed the charts of all patients who underwent laparoscopic colectomy without conversion to open, between October 2010 and December 2012. Patients were divided into two groups, those who underwent traditional multi-incision laparoscopic colectomy (MILC) and those who had SILC. For clarification, patients were randomly allocated to receive either MILC or SILC (table1). In addition, the same surgeons performed both techniques. The characteristics of each group were evaluated according to five criteria: age, gender, American Society of Anesthesiologists (ASA) score, pathology (benign or malignant) and type of procedure - right hemicolectomy (RH), left hemicolectomy ( $\mathrm{LH}$ ) or anterior resection (AR).

The two groups were compared based on intraoperative and early postoperative outcomes. We began by comparing all the patients who underwent SILC to those who had a MILC. Each group was then sub-divided according to the type of procedure (RH/LH/AR) and a comparison was done between SILC and MILC based on each procedure separately. Intraoperative parameters included total operative time, surgical margin Involvement and number of lymph nodes extracted (the pathologist was blinded the surgical technique).The postoperative parameters were length of hospital stay (LOS), 30-day readmission, complication, mortality (thirty-day mortality or in-hospital mortality), and maximum pain score on day of operation and the first postoperative day (POD1). The last two parameters were assessed and recorded by the nursing staff. Pain level was measured using the visual analogue scale (VAS) pain score tool.

\section{Surgical Technique}

We used the GelPort laparoscopic system of Applied Medical (Rancho Santa Margarita, CA, USA) that offered a pseudo abdomen platform for unmatched triangulation of a standard laparoscopic instrument. Usually we performed a $2.5-\mathrm{cm}$ incision in the umbilical area.

\section{Statistical analysis}

Data were statistically analyzed using SPSS v 21.0. Numerical data are presented as means \pm standard deviations. Categorical (ordinal and nominal) variables were analyzed using the chi-squared test, and the Student's t test was used for continual variables.

The duration of admission for each technique was analyzed using the Mann-Whitney non-parametric test. Three surgical approaches were compared individually using the Bonferroni criterion, which maintains an overall type I error rate of 0.05 . 


\section{RESULTS}

Seventy-five patients underwent laparoscopic colectomies at our center between October 2010 and December 2012. Of those 75 procedures, 21 were SILC and 54 were MILC.

As shown in Table 1, the two groups were comparable in terms of age (65.81 \pm 13.26 years in the SILC group and $66.61 \pm 12.92$ years in the MILC group, $p=0.81$ ), gender (M/F 9/12 in the SILC group and 27/27 in the MILC group, $p=0.58$ ),mean ASA score ( $1.89 \pm 0.58$ in the SILC group and $2.11 \pm 0.48$ in the MILC group, $\mathrm{p}=0.13)$, the ratio between the operative procedures (RH/LH/AR-11/9/1 in the SILC group and 25/16/13 in the MILC group, $\mathrm{p}=0.2)$, and pathology $[\mathrm{n}=15(71.42 \%)$ malignant cases in the SILC group and $\mathrm{n}=38(70.4 \%)$ malignant cases in the MILC group , $\mathrm{p}=0.93$ ].

\section{Intraoperative outcomes}

Intraoperative outcomes shown in Table 2 include operative time, surgical margin involvement, and number of lymph nodes extracted (malignant cases only). The mean operative time for SILC was $129 \pm 42$ minutes, compared to $139 \pm 43$ minutes in the MILC; however, this difference was not statistically significant ( $p=0.37$ ). In both groups there was no surgical margin involvement.

Mean amount of lymph node recovered from the pathologic specimen for the SILC group was higher, but not statistically significant from the MILC group $(17.67 \pm 8.05$ VS. $14.7 \pm 7.23$, respectively. $p=0.22)$.

\section{Postoperative outcomes}

As shown in Table 2, the LOS was $8.76 \pm 8.42$ for SILC and $6.74 \pm 2.2$ for the MILC, which was not statistically significant $(\mathrm{p}=0.29)$.

One patient was re-admitted in the SILC group for 24 days due to anastomotic leak after RH. The patient underwent

two more re-operations for peritoneal lavage and abdominal wall closure with a vacuum assisted closure (VAC) system. Two MILC patients were re-admitted (4.76 \% vs. 3.7\%, respectively), the first for three days due to rectal bleeding that stopped spontaneously and the second for two days because of constipation. There was no statistical difference between the groups for hospital re-admittance ( $p=0.83)$.

Six patients in the SILC group developed postoperative complications. Two patients had anastomotic leaks. One of those patients was mentioned above, and the second developed sepsis due to anastomotic leak after LH and underwent six more operations, including peritoneal lavage, colostomy creation, and finally, abdominal closure with a VAC system. Other complications that were encountered were minor, including one contained leak, one hematoma, and two incidents of paralytic ileus. Compared to the group of patients that underwent the SILC procedure, in the MILC group nine patients developed postoperative complications, including two with SSI, one with paralytic ileus, one contracted pneumonia, one needed a blood transfusion, one with pulmonary embolism (PE), one with perioperative atrial fibrillation (AF) and two more were readmitted as described before $(28.57 \%$ vs. $16.6 \%)$. There was no statistical difference between the groups for postoperative complications $(\mathrm{p}=0.1)$.

The fourth parameter that was evaluated was maximum VAS pain score on the day of the operation and on the first POD. Mean VAS pain scores in the SILC group were $2.61 \pm 3.2$ and $2.26 \pm 2.66$, respectively. Those results were not statistically different from the MILC group: $1.37 \pm 2.57$ and $2.65 \pm 2.69$, respectively $(\mathrm{p}=0.29$, $\mathrm{p}=0.32$ ). 
There were no deaths in either the MILC or the SILC group.

\section{SILC vs. MILC - specific procedure}

Table 3 shows the comparison of the two techniques for RH, LH, and AR separately. When performing RH there was a trend $(\mathrm{p}=0.08)$ of better oncological results with a higher mean number of lymph nodes extracted $(23.5 \pm 3.16$ vs. $17.19 \pm 6.93)$. In addition, the LOS was lower in the SILC compared to the MILC group (5.91 \pm 3.59 vs. $6.48 \pm 1.76$, respectively). This difference was statistically significant ( $p=0.05)$.

Other parameters that were evaluated for RH, LH, and AR showed no statistical significance.

Table 1. Comparison of patients' characteristics between SILC and MILC

\begin{tabular}{|l|l|l|l|}
\hline & SILC & MILC & $\mathrm{P}$ \\
\hline $\mathrm{N}$ & 21 & 54 & \\
\hline Male/Female ratio & $9 / 12$ & $27 / 27$ & $\mathrm{P}=0.58$ \\
\hline Age , mean \pm SD & $65.81 \pm 13.26$ & $66.61 \pm 12.92$ & $\mathrm{P}=0.81$ \\
\hline ASA score, mean \pm SD & $1.89 \pm 0.58$ & $2.11 \pm 0.48$ & $\mathrm{P}=0.13$ \\
\hline Pathology, n (\%) & & & \\
\hline Malignant & $15(71.42)$ & $38(70.4)$ & $\mathrm{P}=0.93$ \\
\hline ype of procedure & & & \\
\hline Right hemicolectomy & 11 & 25 & $\mathrm{P}=0.2$ \\
\hline Left hemicolectomy & 9 & 16 & \\
\hline Anterior resection & 1 & 13 & \\
\hline
\end{tabular}

Table 2. Intraoperative and postoperative outcomes, comparison between SILC and MILC

\begin{tabular}{|c|c|c|c|}
\hline & SILC & MILC & $\mathbf{P}$ \\
\hline \multicolumn{4}{|l|}{ Intraoperative } \\
\hline Operative time $(\mathrm{min})$, mean \pm SD & $129 \pm 42$ & $139 \pm 43$ & 0.37 \\
\hline Surgical margin involvement & No & No & \\
\hline $\begin{array}{l}\text { Number of lymph nodes extracted } \\
\text { mean } \pm \text { SD } \\
\text { Range }\end{array}$ & $\begin{array}{l}17.67 \pm 8.05 \\
11-32\end{array}$ & $\begin{array}{l}14.67 \pm 7.23 \\
6-30\end{array}$ & 0.22 \\
\hline \multicolumn{4}{|c|}{ Postoperative (within 30 days from surgery) } \\
\hline $\begin{array}{l}\text { LOS (days), mean } \pm \text { SD } \\
\text { Median } \\
\text { Range }\end{array}$ & $\begin{array}{l}8.76 \pm 8.42 \\
5 \\
3-35\end{array}$ & $\begin{array}{l}6.74 \pm 2.2 \\
6 \\
4-14\end{array}$ & 0.29 \\
\hline Readmission ${ }^{\S}$ & $1(4.76)$ & $2(3.7)$ & 0.83 \\
\hline Operative day VAS score, mean \pm SD & $2.61 \pm 3.2$ & $1.37 \pm 2.57$ & 0.29 \\
\hline POD1 VAS score, mean \pm SD & $2.26 \pm 2.66$ & $2.65 \pm 2.69$ & 0.32 \\
\hline Complications $^{\S}$ & $6(28.57)$ & $9(16.6)$ & 0.109 \\
\hline Mortality & 0 & 0 & \\
\hline
\end{tabular}

$\S$ Number and percentage, respectively 
Table 3. Specific outcomes according to the type of surgery, a comparison between SILC and MILC.

\begin{tabular}{|c|c|c|c|}
\hline & SILC & MILC & $\mathbf{P}$ \\
\hline \multicolumn{4}{|l|}{$\mathrm{RH}$} \\
\hline Operative time $(\mathrm{min})^{\mathrm{a}}$ & $125 \pm 22$ & $125 \pm 31$ & 0.98 \\
\hline Number of lymph nodes extracted ${ }^{a}$ & $23.5 \pm 3.16$ & $17.19 \pm 6.93$ & 0.08 \\
\hline LOS(days) ${ }^{\mathrm{a}}$ & $5.91 \pm 3.59$ & $6.48 \pm 1.76$ & 0.05 \\
\hline Readmission $^{\S}$ & $1(9.09)$ & 0 & 0.13 \\
\hline Operative day VAS score ${ }^{a}$ & $2.71 \pm 3.49$ & $1.47 \pm 2.53$ & 0.33 \\
\hline POD1 VAS score ${ }^{a}$ & $1 \pm 2.34$ & $2.55 \pm 2.85$ & 0.16 \\
\hline Complications ${ }^{\S}$ & $3(27.3)$ & $4(16)$ & 0.43 \\
\hline \multicolumn{4}{|l|}{ LH } \\
\hline Operative time $(\mathrm{min})^{\mathrm{a}}$ & $126 \pm 55$ & $126 \pm 23$ & 0.97 \\
\hline Number of lymph nodes extracted ${ }^{a}$ & $13.5 \pm 6.11$ & $14.5 \pm 7.99$ & 0.75 \\
\hline 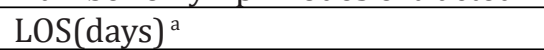 & $11.78 \pm 11.73$ & $6.13 \pm 1.54$ & 0.18 \\
\hline Readmission $^{\S}$ & 0 & 0 & Error \\
\hline Operative day VAS score ${ }^{a}$ & $2.5 \pm 3.88$ & $2.8 \pm 2.75$ & 0.86 \\
\hline POD1 VAS score ${ }^{a}$ & $1.67 \pm 3.2$ & $2.63 \pm 2.72$ & 0.53 \\
\hline Complications $^{\S}$ & $2(22.22)$ & $2(12.5)$ & 0.52 \\
\hline \multicolumn{4}{|l|}{ AR } \\
\hline Operative time $(\mathrm{min})^{\mathrm{a}}$ & 202 & $180 \pm 56$ & Error \\
\hline Number of lymph nodes extracted ${ }^{a}$ & 16 & $11.5 \pm 5.8$ & Error \\
\hline LOS (days) $^{\mathrm{a}}$ & 13 & $8 \pm 3.13$ & 0.18 \\
\hline Readmission $\S$ & 0 & 2 & Error \\
\hline Operative day VAS score ${ }^{a}$ & & $3.17 \pm 2.63$ & Error \\
\hline POD1 VAS score ${ }^{a}$ & 3 & $2.67 \pm 2.55$ & Error \\
\hline Complications $^{\S}$ & 1 & $3(23)$ & 0.107 \\
\hline
\end{tabular}

$\S$ Number and percentage, respectively

${ }^{a}$ Mean \pm SD

\section{DISCUSSION}

Adaptation of the SILC approach has been reported in case reports [17-18], small case series [19], and case-matched series [20]. These reports have demonstrated improved cosmetic outcome, decreased early postoperative pain, and shorter LOS for patients who underwent the SILC procedure. In our study, we compared the SILC and standard MILC approaches in terms of the intraoperative and postoperative outcomes.

Regarding intraoperative outcomes, we found that the operative times for the SILC and MILC procedures were equivalent. In theory, the use of a single incision may reduce the surgeon's maneuvering space, and the lack of triangulation could compromise surgical exposure, leading to the potential risk that the surgeon may not fulfill all oncological criteria. Despite these potential drawbacks, our results showed that neither group had surgical margin involvement and the mean number of lymph nodes extracted was even higher when using the SILC approach (17.6 vs. 14.6), but this difference was not statistically significant.

The postoperative outcomes that were evaluated included LOS, 30-day readmission, postoperative pain, complications, and mortality. We report similar outcomes between the two techniques, with no statistically significant advantages to one or the other technique. For clarification, we believe that in both cases in the SILC group, where an anastomotic leak had occurred it was not related to the surgical technique: The patient after LH that developed a post-operative leak had an extra-corporal anastomosis and the leak was found in the colon 
stump and not in the anastomosis. In the second case (after RH), we believe that the cause is related to an anatomical variant of blood supply to the right colon that led to vascular insufficiency of the anastomosis, which probably caused leakage.

In summary, we found that the SILC procedure produced equivalent results based on operative time, oncological results, LOS, 30-day readmission, postoperative pain, complications, and mortality. Our findings corroborate those of prior studies [21-24] and lead to the conclusion that using the single port procedure for large bowel resections is a feasible and safe option.

We also compared each procedure - RH, LH, and AR - separately in terms of the operative outcomes of the single incision vs. the multi-incision approach. With the exception of the number of abdominal wall incisions, the SILC and MILC operative procedures are basically the same. When comparing the data for RH done in a SILC procedure, we found a statistical trend $(\mathrm{p}=0.08)$ of better oncological results with a higher number of lymph nodes extracted compared to MILC (23.5 vs. 17.19). Prior reports show similar results with equivalent oncological result in single incision RH [12-13, 15-16, 25]. A possible reason for the oncological advantage found for RH and absent in the other colectomies could be that the amount of meso-colon that is resected in the single port technique is higher than the MILC, since the single port enables extraction of the colon through an umbilical incision such as the open technique.

The evaluation of the $\mathrm{RH}, \mathrm{LH}$ and AR procedures in terms of postoperative outcomes showed a statistically significant advantage ( $\mathrm{p}=0.05)$, in the form of decreased LOS (5.9 vs. 6.5), to using the single incision approach. Papaconstantinou et al. [20] and Poon et al. [26] also reported a decreased LOS in single incision RH. Both have suggested that the cause could be decreased postoperative pain. Our data showed a lower mean VAS score in the first POD (1 vs. 2.55), but this difference was not statistically significant. A possible bias could be due to the data being taken from the nursing stuff reports, in which postoperative pain was not reported for all patients.

When evaluating LH and AR in the single incision approach, no statistically significant difference was found. The use of single port in resection of the left colon was mostly reported in sigmoidectomy [27-30]. Those reports concluded that the single port approach is feasible and safe without substantially increasing morbidity and mortality. Our study reinforced those conclusions, suggesting that the use of single port is safe for both LH and AR, but our results did not show any statistically significant benefits.

\section{CONCLUSIONS}

The use of the single incision approach for bowel resections is feasible and safe. When performing the RH procedure, SILC has statistically significant advantages over the traditional MILC approach in terms of reduced LOS and better oncological results (higher number of lymph nodes extracted). Given our findings, we believe that the SILC technique is an effective alternative to MILC when performing RH. However, the efficiency of the technique in LH or AR is still questionable and needs further evaluation.

\section{Disclosure}

Dr. Idit Melnik, Dr. Oleg Dukhno, Mrs. Ornit Cohen, Dr. Dimitry Goldstein, Dr. Moris Batumsky and Prof. Boris Yoffe have no conflicts of interest or financial ties to disclose.

\section{REFERENCES}

Lacy AM, Garcia-Valdecasas JC, Pique JM, Delgado S, Campo E, Bordas JM, Taure P, Grande L, Fuster J, Pacheco JL (1995) Short-term outcome analysis of a randomized study comparing laparoscopic vs. open colectomy for colon cancer. Surg Endosc 9:1101-1105.

Braga M, Vignali A, Gianotti L, Zuliani W, Radaelli G, Gruarin P, Dellabona P, Di Carlo V (2002) Laparoscopic versusopen colorectal surgery: a randomized trial in short term outcome. Ann Surg 236:759-766.

Volume 2

Page 6 
Guller U, Jain N, Hervey S, Purves H, Pietrobon R (2003) Laparoscopic vs open colectomy: outcomes comparison based on large nationwide data bases. Arch Surg 138:1179-1186.

Delaney CP, Kiran RP, Senagore AJ, Brady K, Fazio VW (2003) Case-matched comparison of clinical andfinancial outcome after laparoscopic or open colorectal surgery. Ann Surg 238:67-72.

The Clinical outcomes of surgical therapy study group. A comparison of laparoscopically assisted and open colectomy for colon cancer. (2004) N Engl J Med 350:2050-2059.

Pelosi MA, Pelosi MA 3rd (1992) Laparoscopic supracervical hysterectomy using a single-umbilical puncture(mini-laparoscopy). J Reprod Med 37:777-784.

Bresadola F, Pasqualucci A, Donini A, Chiarandini P, Anania G, Terrosu G, Sistu MA, Pasetto A (1999) Elective transumbilical compared with standard laparoscopic cholecystectomy. Eur J Surg 165:29-34.

Bucher L, Pugin F, Morel P (2008) Single port access laparoscopic right hemicolectomy. Int J Colorectal Dis 23:1013-1016.

Remzi FH, Kirat HT, Kaouk JH, Geisler DP (2008) Single-port laparoscopy in colorectal surgery. Colorectal Dis 10:823-82.

Rieger NA, Lam FF (2010) Single-incision laparoscopically assisted colectomy using standard laparoscopic instruments. Surg Endosc 24:888-890.

Merchant AM, Lin E (2009) Single-incision laparoscopic right hemicolectomy for a colon mass. Dis Colon Rectum 52:1021-1024.

Ramos-Valadez DI, Patel CB, Ragupathi M, Bartley Pickron T, Haas EM (2010) Single-incision laparoscopic right hemicolectomy: safety and feasibility in a series of consecutive cases. Surg Endosc 24:2613-2616.

Law W, Fan J, Poon J (2010) Single-incision laparoscopic colectomy: early experience. Dis Colon Rectum 53:284288.

Brunner W, Schirnhofer J, Waldstein-wartenberg N, Frass R, Weiss H (2010) Single incision laparoscopic sigmoid colon resections without visible scar: a novel technique. Colorectal Dis 12:66-70.

Adair J, Gromski MA, Lim RB, Nagle D. (2010) Single-incision laparoscopic right colectomy: experience with 17 consecutive cases and comparison with multiport right colectomy. Dis Colon Rectum 53:1549-1554.

Waters JA, Guzman MJ, Fajardo AD, Selzer DJ, Wiebke EA, Robb BW, George VV (2010) Single-port laparoscopic right colectomy: a safe alternative to conventional laparoscopy. Dis Colon Rectum 53:1467-1472.

Bucher P, Pugin F, Morel P. (2009) Single-port accsess laparoscopic radical left colectomy in humans. Dis colon rectum 52:1797-1801.

Remzi FH, Kirat HT, Geisler DP (2009) Laparoscopic single-port colectomy for sigmoid cancer. Tech Coloproctol 14(3):253-5.

Chambers W, Bicsak M, Lamparelli M, Dixon A (2009) Single-incision laparoscopic surgery (SILS) in complex colorectal surgery: A technique offering potential and not just cosmesis. Colorectal Dis 13(4):393-8.

Papaconstantinou HT, Sharp N, Thomas JS (2011) Single-incision laparoscopic right colectomy: a casematched comparison with standard laparoscopic and hand-assisted laparoscopic techniques. J of the American College of Surgeons 213:72-82. 
Trakarnsanga A, Akaraviputh T, Wathanaoran P, Phalanusittheoha C, Methasate A, Chinswangwattanakul V (2011) Single-incision laparoscopic colectomy without using special articulating instruments: an initial experience. World J of Surgical Oncology 9:162.

Champagne BJ, Papaconstantinou HT, Parmar SS, Nagle DA, Young-fadok TM, Lee EC, Delaney CP (2012) Single-incision versus standard multiport laparoscopic colectomy: a multicenter, case-controlled comparison. Ann Surg 255:66-69.

Huscher CG, Mingoli A, Sgarzini g, Mereu A, Binda B, Brachini G. Trombetta S (2011) Standard laparoscopic versus single-incision laparoscopic colectomy for cancer: early results of a randomized prospective study. Am J Surg 204(1):115-20.

Lu CC, Lin SE, Chung KC, Rau KM (2012) Comparison of clinical outcome of single incision laparoscopic surgery using a simplified access system with conventional laparoscopic surgery for malignant colorectal disease. Colorectal Dis 14(4):e171-e176.

Boni L, Dionigi G, Cassinotti E, Gluseppe MD, Diurni M, Rausei S, Cantore F, Dionigi R (2010) Single incision laparoscopic right colectomy. Surg Endosc 24:3233-3266.

Poon JTC, Cheung CW, Fan JKM, LO OSH, Law WL (2012) Single-incision versus conventional laparoscopic colectomy for colonic neoplasm: a randomized, controlled trial. Surg Endosc 26:2729-2734.

Vestweber, Alfes A, Paul C, Haaf F, Vestweber KH (2010) Single-incision laparoscopic surgery: a promising approach to sigmoidectomy for diverticular disease. Surg Endosc 24: 3225-3228.

Ramous-Valadez D, Ragupathi M, Nieto J, Patel CB, Miller S, Pickron TB, Haas EM (2012) Single-incision versus conventional laparoscopic sigmoid colectomy: a case matched series. Surg Endosc 26:96-102.

Uematsu D, Akiyama G, Matsuure M, Hotta K (2010) Single-access laparoscopic colectomy with a novel multiport device in sigmoid colectomy for colon cancer. Dis Colon Rectum 53:596-501.

Bucher P, Pugin F, Morel P (2010) Transumbilical single incision laparoscopic sigmoidectomy for benign disease. Colorectal Dis 12:61-65.

A Comparison between Single Port and the Traditional Multiport Technique for Colon Resections Idit Melnik MD, Oleg Dukhno MD, Ornit Cohen M.MED Sc , Dimitry Goldstein MD, Moris Batumsky,Boris Yoffe MD FACS

Citation: Idit Melnik MD, Oleg Dukhno MD, Ornit Cohen M.MED Sc , Dimitry Goldstein MD, Moris Batumsky,Boris Yoffe MD FACS. "A Comparison between Single Port and the Traditional Multiport Technique for Colon Resections". American Research Journal of Medicine and Surgery, Volume 2, 2016; pp:1-8

Copyright (c) 2016 Idit Melnik MD, Oleg Dukhno MD, Ornit Cohen M.MED Sc , Dimitry Goldstein MD, Moris Batumsky, Boris Yoffe MD FACS. This is an open access article distributed under the Creative Commons Attribution License, which permits unrestricted use, distribution, and reproduction in any medium, provided the original work is properly cited. 